Neurosurg Focus 16 (1):Introduction, 2004, Click here to return to Table of Contents

\title{
History of spinal surgery
}

\author{
Dennis E. MCDonnell, M.D. \\ Department of Neurosurgery, Gundersen Lutheran Medical Center, La Crosse, Wisconsin
}

The History Section of the American Association of Neurological Surgeons (AANS) is hosting this issue of $\mathrm{Neu}$ rosurgical Focus. Spinal surgery is such an integral part of American neurosurgery that it is appropriate that we ex-amine at least some aspects of its development. Advancements in spinal surgery continue to be made at an ever-quickening pace. It is amazing that such scientifically based concepts of pathology and diseases involving the spine really did not emerge until the last decade of the 19th century.

After a brief overview, this issue is enhanced by a scholarly discussion of what was known of spinal disorders in ancient, medieval, and Renaissance eras. Additional papers follow the progress of this field through the Napoleonic and American Civil wars and into the era of World War I.

The lumbar disc and its relationship to sciatica are discussed from a historical perspective. Insight into lumbar disc disease launched spinal surgery into the modern era.

The modern era of spinal surgery has been spurred on by imaging technologies, which allow direct visualization of spinal anatomy and pathological conditions. The natural sequence of events following our newly found knowledge based on neuroimaging was direct surgical treatment of pathological conditions of the spine by eradication of the offending lesion and spinal stabilization. This review begins with an excellent discourse on the historical development of anterior cervical plating designs. The evolution of principles of posterior segmental occipitocervical, axial, and subaxial cervical fixation methods is then discussed, followed by the development of posterior thoracic instrumentation.

Anterior approaches to the spine have provided unique access to the vertebral column that has made a major contribution to our understanding of adjacent spinal anatomy and direct decompression and fixation of the spine. These are discussed as well.

Finally, we obtain a glimpse of the future with the description of minimally invasive endoscopic procedures on the spine. We also see a helpful adjunct for axial screw placement in the treatment of Type II odontoid fractures.

This issue gives the reader a broad and insightful review of developments in spinal surgery. As the topic editor, I wish to extend my sincere gratitude to the authors who worked hard and diligently in contributing their manuscripts to this issue of Neurosurgical Focus. I also want to thank my associate editors: William C. Bergman, M.D., Mark Preul, M.D., and Drew Sullivan, M.D., who kindly assisted me in reviewing the manuscripts.

I invite interested readers to join the History Section of the AANS. 